\title{
مستخلص الحنزير لصناعة الأدوية الكبسولة: الاستحالة في ضوء مقاصد الشريعة
}

\section{Pork Extract for Manufacturing Capsulated Medicines: Istihâlah in the Light of Maqāsid Sharī'ah}

\author{
Saheed Abdullahi Busari (Corresponding Author)* \\ Ahmad Muhamad Husni**
}

\begin{abstract}
Bringing benefit and repelling harm is one of the main objectives embedded in the divine law of Shariah. The law of Shariah came in its entirety for the preservation of fundamental principles of Allah on the creation such as the five maqāsid al-sharī'ah principles. Since the dawn of the scientific revolution, genetic engineering has triggered several debates at different levels among the stakeholders. Clearly, there are opinions between the process of transformation and mere transmutation of the substance, some of which are subject to consensus and some differs. This study aims to analyze the juristic implication
\end{abstract}

* Assistant Professor, Kulliyyah of Islamic Revealed Knowledge and Human Sciences, International Islamic University Malaysia, P.O. Box 10, 50728, Kuala Lumpur. sahheed@iium.edu.my

** Assistant Professor, Kulliyyah of Islamic Revealed Knowledge and Human Sciences, International Islamic University Malaysia, P.O. Box 10, 50728, Kuala Lumpur. ahmedking@iium.edu.my 
of the permissibility of using gelatin extracted from pig parts in the pharmaceutical industry. The study adopted the inductive approach to collect the information recorded in contemporary literature in this regard and then followed by a comparative analytical study to highlight the agreed and disagreed facts between Shariah sources and other sciences. The most important note is that in the event of a choice, consuming foods and drinks containing pork gelatin is not permissible. By the same analogy, the capsulated medicines cannot be taken, and this study is purely for the case when it is necessary and there is no alternative.

Keywords: medicines, capsules, gelatin extracts, maqāsid alsharī'ah, health science

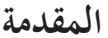

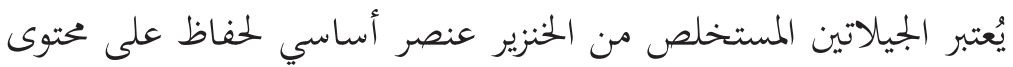

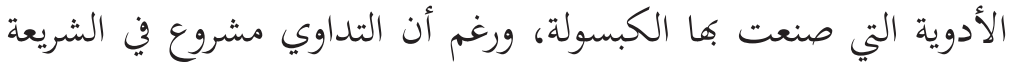

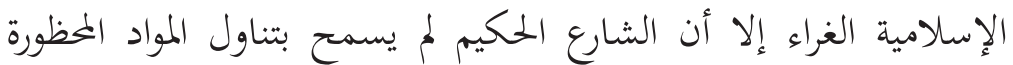

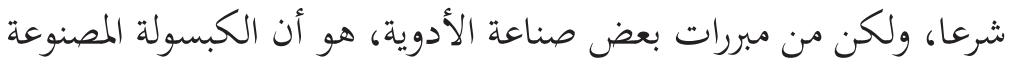

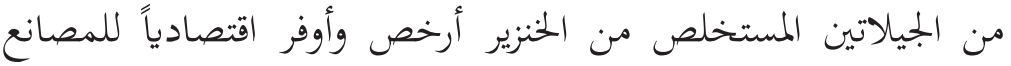

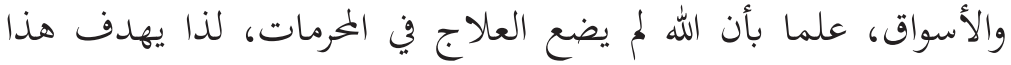
البحث إلى تسليط الضوء على حقيقة الكبسولة المصنوعة من الجيلاتين

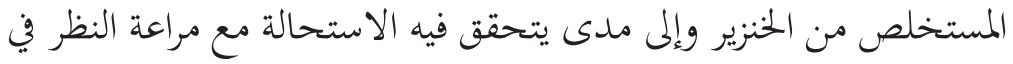

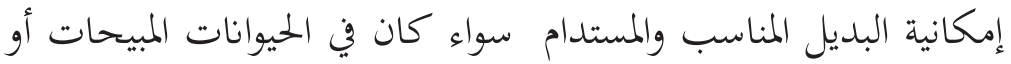
النباتات الأخرى، والدراسة يتمحور حول درجة الاحتياج مصنع الأدوية

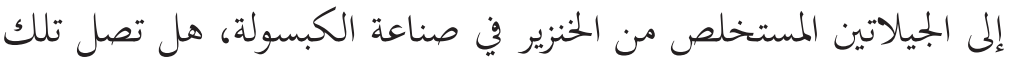

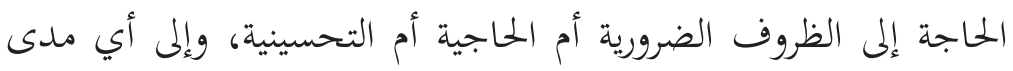
تعتبر صلاحية البدائل الموجودة وفاعليتها في تحقيق الحفاظ على الأدوية. 
ومن الدراسات السابقة التي تناولت أحكام الكبسولة المصنوعة من الجيلاتين المستخلص من الحنزير هو ما تفضل به محمد جمال الدين وأخرون

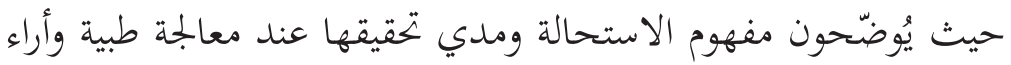

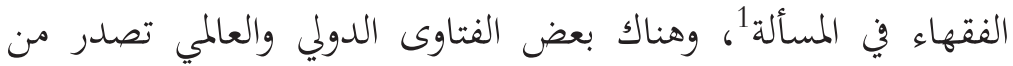

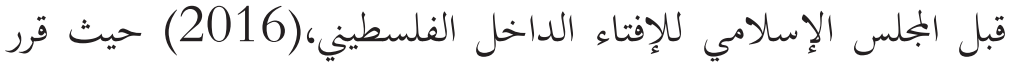
مجلسه بجواز استخدام الجيلاتين المستخلصة من الجلود أو الجساء العظام الحيوانية

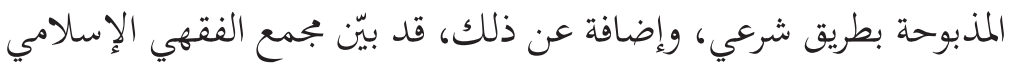

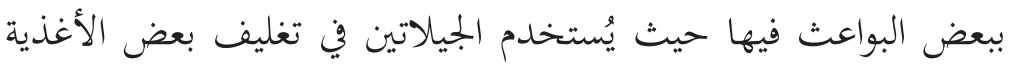

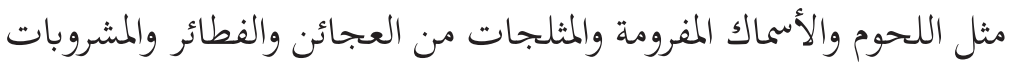

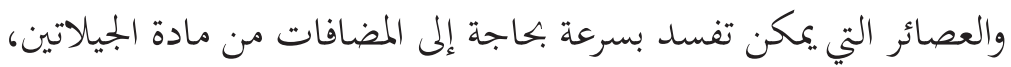

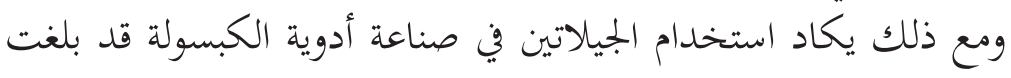

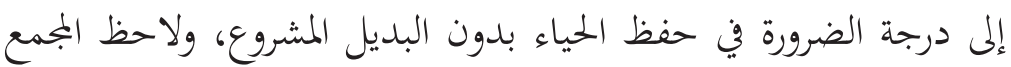

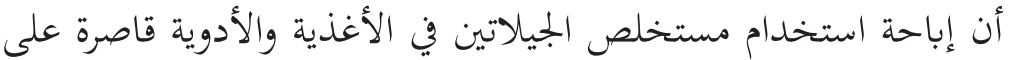

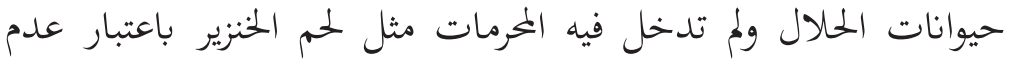

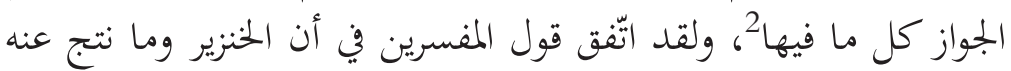

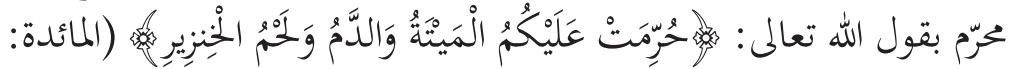

ولحم الخنزير في الآية بمعنى كل ما في الخنزير من لحمها وصحفها ودمها وعظمها ومع ذلك ذهب بعض بعض الباحثين حقيقة عملية الاستحالة

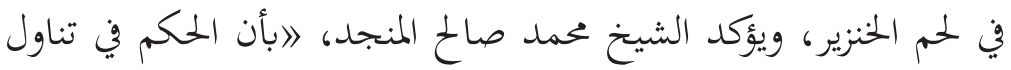

Mohammad Aizat Jamaludin, Mohd Anuar Ramli, Dzulkifly Mat Hashim \& Suhaimi Ab Rahman, "Fiqh Istihalah: Integration of Science and Islamic Law," Revelation and Science 2 (2012), 117123.

2 Mujtama Fiqh, "al-Qarār al-Thālith bi Sha'n Istifādāṭ al-Muslimīn min 'Iẓami al-Ḥayawanāt wa Julūdihā fỉ Șinā’h al-Jalātin," (Qarārāt al-Dawrah al-Khāmisah Asharah al-Mun'aqidah, Makkah, $31^{\text {st }}$ Oct. 1988), 316. 
الجلاتين المستخلص من المحرمات موقوف على حقيقة استحالة في مآل

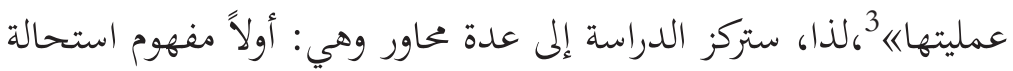

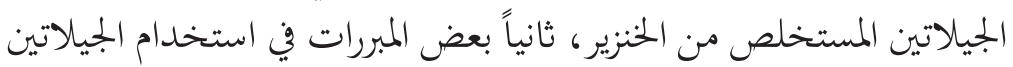

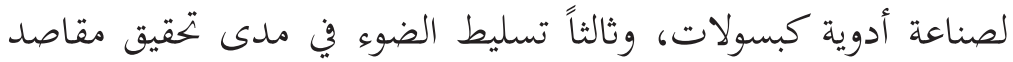

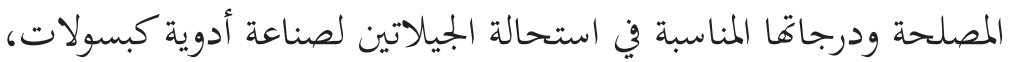
تمّ نخلص من ذلك نتائج الدراسة وخاتمة.

\section{حقيقة استحالة الجيلاتين المستخلص من الخنزير}

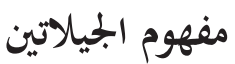

وفي عصر الحديث، هناك عدّة قضايا تعلّقت بالمنتجات الغذائية والأدوية

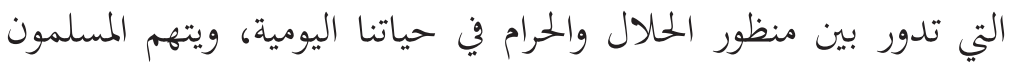

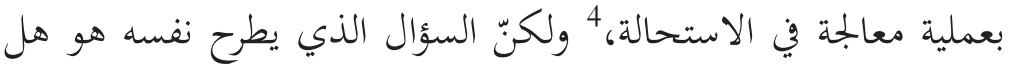

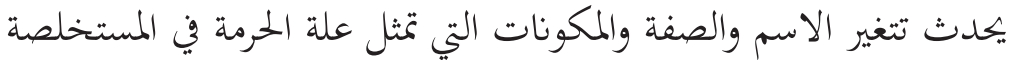

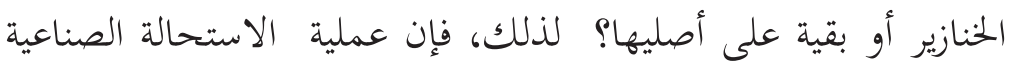

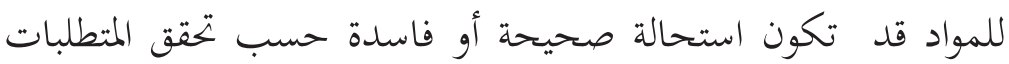

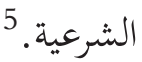

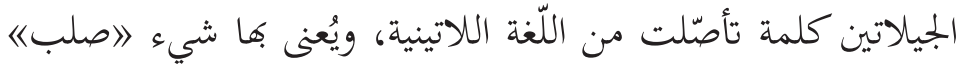

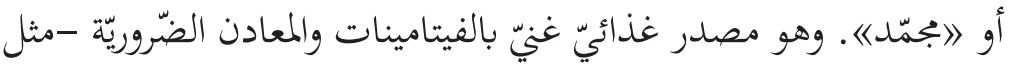

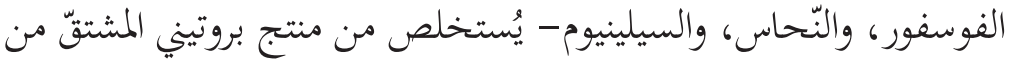

3 Al-Munjid, Muhammad Șāliḥ, Hukm al-`Amal fī Tawzīe Mawād Gadhāiyyah tạ̣tawī 'alā Mādah al-Jalātin al-Mustakhrijah min alKhinzīr, (2017).

4 Yoneciti, Istiḥālah al-Jalātin Bayn al-'Ilm wa al-Fiqh, Halal Certification from Turkey, (2015), http://www. halalcertificationturkey.com/ar/2015/01/28.

5 'Uthmān, 'Abd al-Karīm, al-Jalātin wa Wuqū' al-Istihāalah: Dirāsah

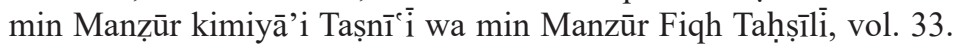
50, (Lahore, Majallah al-Adwā', 2018), 215. 
الكولاجين المأخوذ من مكوّن جسم الحيوان. بل أثبت بعض دراسات

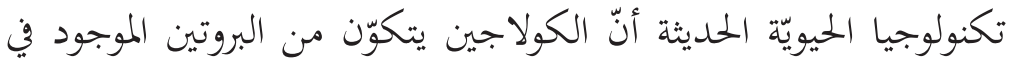
جسم الإنسان والحيوانات، إلّا أنّه يوجد بكثرة في الجلد واندين والعظام والأوتار

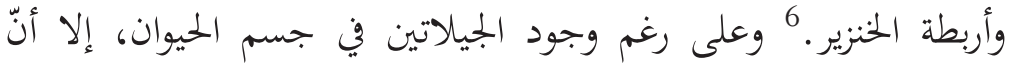

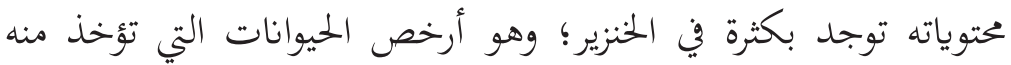

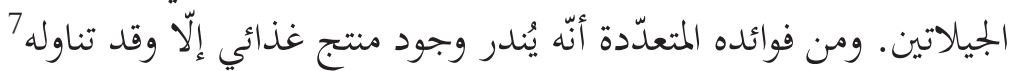

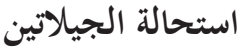

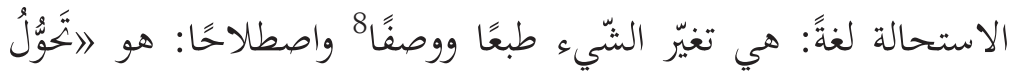

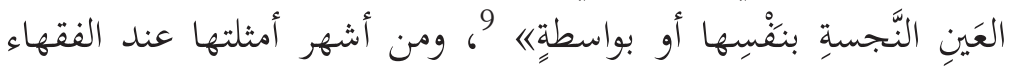

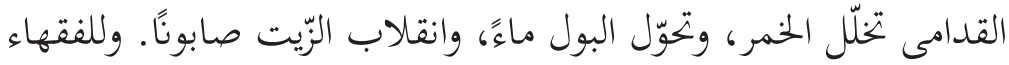

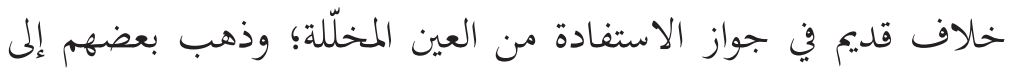
جوازها إذا تغيرت وصارت خلا بنفسها بدون اختلاط بمواد أخرى، لتحقّق تحوّها إلى عين طاهرة فأضحت إذا تغرت وصان لم يكن بها وصف النجاسة. 10

\section{صورة استحالة الجيلاتين المستخلص من الخنزير}

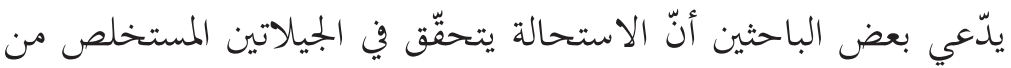

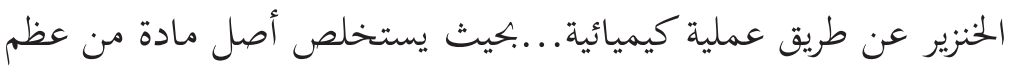

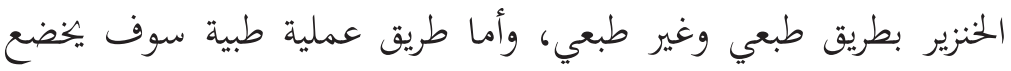

Ibid. 218.

7 Mariod, Abdalbasit Adam \& Adam, Hadia Fadol, "Review: Gelatin, Source, Extraction and Industrial Applications," Acta Sci. Pol., Technol. Aliment 12, no. 2 (2013), 135-147.

8 Al-Fayūmí al-Muqrí, Aḥmad bin Muḥammad bin `Alī, al-Miṣbāḥ alMunir fï Gharīb al-Sharḥ, (Bairūt: Maktabat al- Lubnān, 1987), 157.

9 Zuhailī, Wahbah, al-Fiqh al-Islāmō wa Adillatuh (Suriyah, Dār alFikr, 1985), 1: 250.

10 Ibn `Abd al-Bar, Abū `Amr Yūsuf bin `Abdillah, al-Istidhkār: AlJāmi`li Madhā'ib al-Fuqahā' (Qāhirah: Dār al-Wa'y, 1993), 172. 
مستخلص من عظم الحنزير في المادة الكيميائية لفترة معينة قبل الحصول

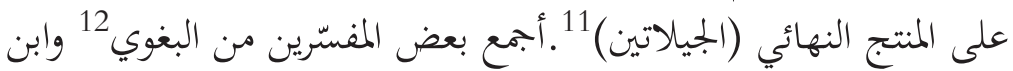

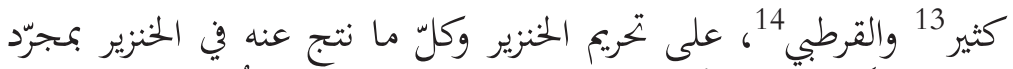

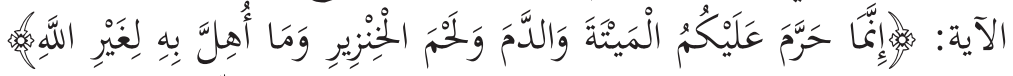

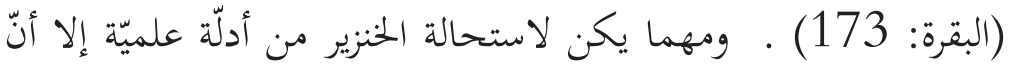

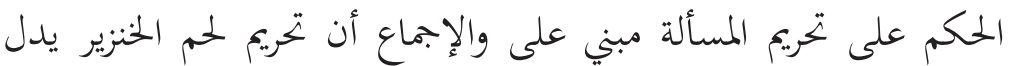

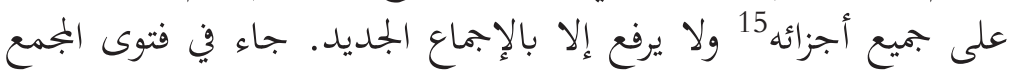

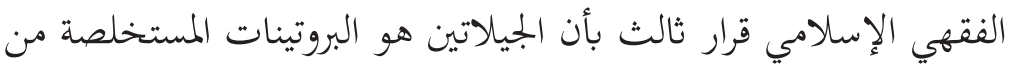

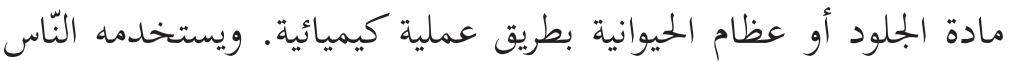

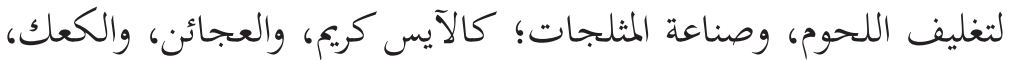

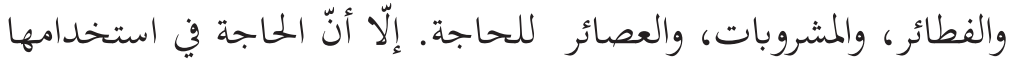

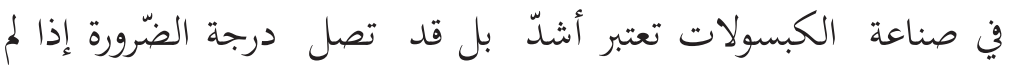

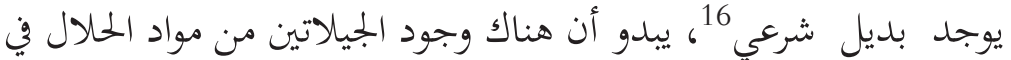

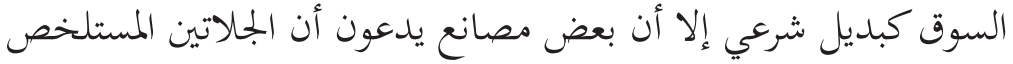

11 Abdul Rahim, Halimah, Hasan Ahmad \& Mohd Hasbi Ab. Rahim, "Theoretical Concept of Istihălah in Gelatine Application: A Review," International Social Science and Humanities Journal 3, no. 2 (2020), 142.

12 Al-Baghawī, al-Husayn bin Mas'ūd, Ma ālim Tanzīl fì Tafsìr alQur'ān (Bayrūt, Dār Ihyyā' Turāth al- 'Arabìi, 1997), 183.

13 Ibn Kathīr, Isma'ìl bin 'Umar, Tafsìr-al-Qur'ān al- 'Azìm, ed. S. bin M. Al-Salāmah (Bayrūt: Dār Țībah, 1997), 172-173.

14 Al-Qurțubì, Muḥammad bin Ahmad, al-Jāmi`li Ahkām al-Qur'ān, ed. 'Abd Allah bin 'Abd al-Muḥsin al-Turqī (Qahirah: al-Risālah Publisher, 2006), 203.

15 Al-Razī, Muḥammad bin 'Umar, Mafātīh al-Ghayb (Dimashq: Dār al-Fikr, 1981), 5: 12.

16 Mujtama Fiqh, al-Qarār al-Thālith bi Sha'n Istifādāṭ al-Muslimīn min 'Iẓami al-Hayawānāt wa Julūdihā fì Șinā’h al-Jalātin, (Makkah, Qarārāt al-Dawrah al-Khāmisah `Asharah 31 ${ }^{\text {st }}$ Oct. 1988), 316. 


\section{من الخنزير أرخص وأفضل اقتصاديا17.}

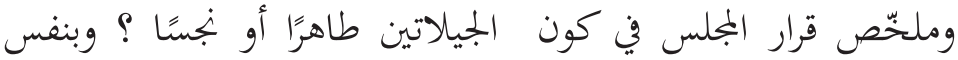

الطريقة قرّر المجمع الفقه الإسلامي جواز استعمال الجيلاتين المستخرج

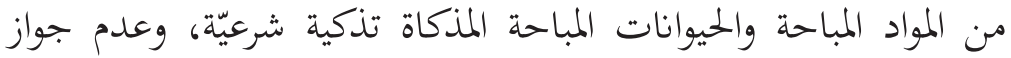

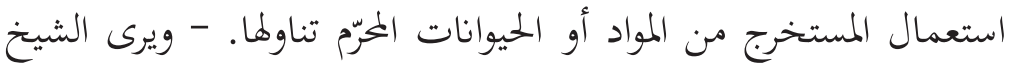

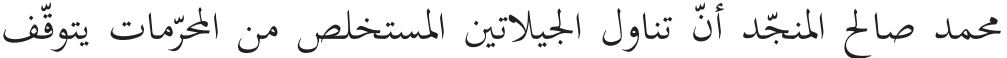

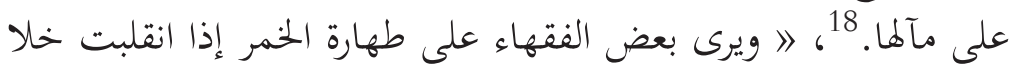

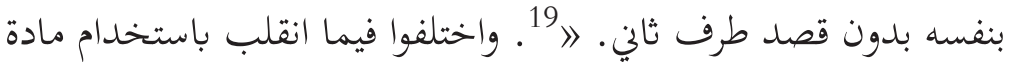

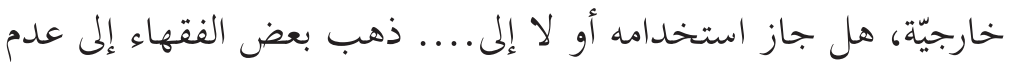

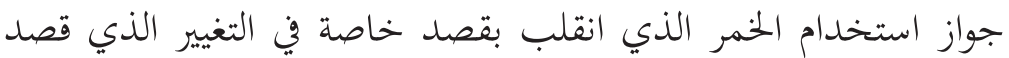

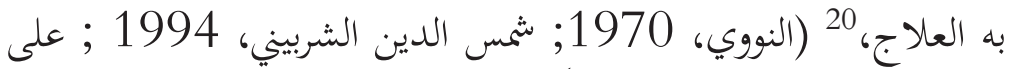

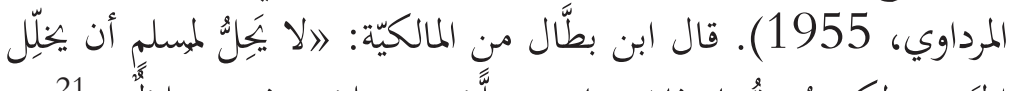

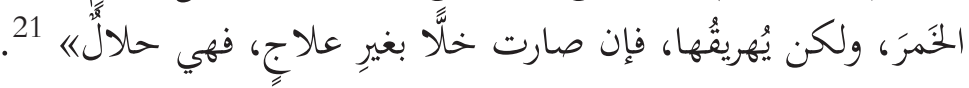

17 Hamadah Nur Lubis, Noor Faizah Mohd-Naim, Nur Nazurah Alizul \& Minhaz Uddin Ahmed, From market to food plate: Current trusted technology and innovations in halal food analysis, vol. 58, (Columbus USA, Trends in Food Science \& Technology 2016), 5568.

18 Al-Munjid, Muhammad Șāliḥ, Ḥukm al-`Amal fī Tawz̄̄e Mawād Gadhāiyyah taḥtawī 'alā mādah al-Jalātin al-Mustakhrijah min alKhinzīr, (2017)

19 Al-Bābiratī, Muhammad bin Muhammad, al-'Ināyah Sharh alHidāyah (Dimashq: Dār al-Fikr, n.d.), 10: 106.

20 Al-Nawawi, Yahyā bin Sharaf, al-Majmū' Sharh al-Muhadhdhab, ed. Muhamad Najīb Muțīe (Juddah, Maktabah al-Irshād, 1970), 2: 578.

21 Ibn Bațāal, 'Alì bin Khalaf, Sharḥ Șaḥ̄h al-Bukhārī li Ibn Baț̣āl (Riyāḍ, Maktab al-Rushd, 2003), 6: 346. 
صورة استحالة الجيلاتين

كلمة استحالة هي تغير من حالة إلى أخرى ومن صفة معينة إلى جديدة، 22

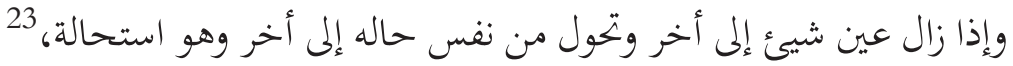

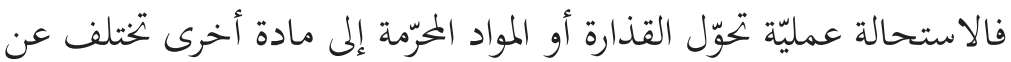

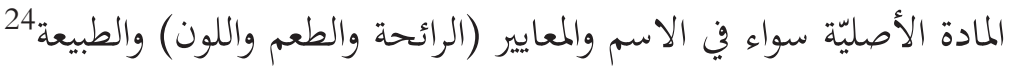

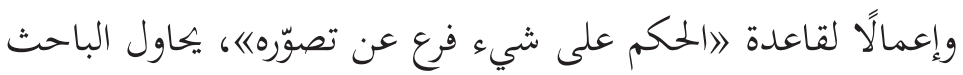

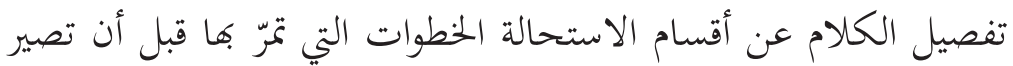

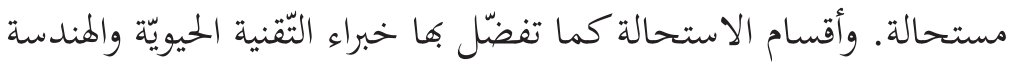

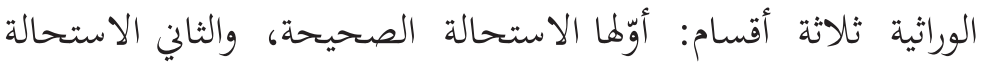

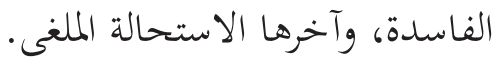

1) الاستحالة الصحيحة: هي عملية تغيير وتحويل خليط من المواد الحلال

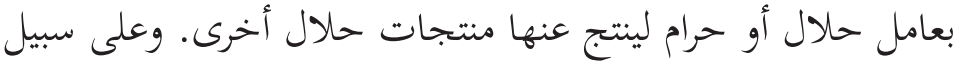

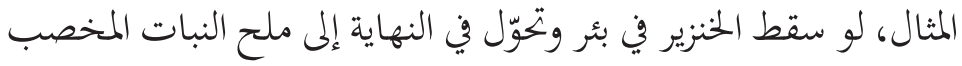

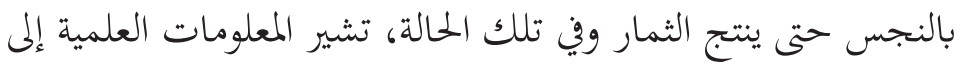

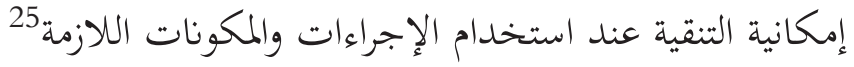

2) الاستحالة الفاسدة: هي عملية خلط مواد الحلال أو الحرام مع عوامل

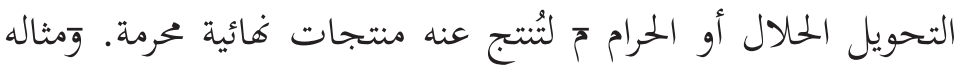

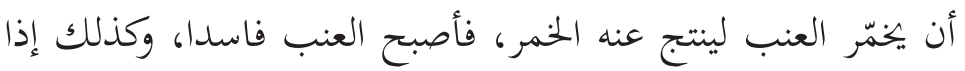

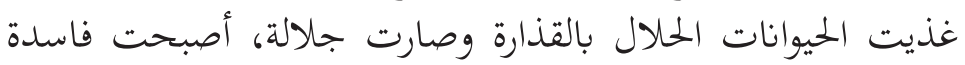

22 Al-Fayūmī al-Muqrī, al-Miṣbāḥ al-Munìr fỉ Gharīb al-Sharḥ, 157.

23 Ibn Manẓūr, Muhammad bin Mukrim, Lisān al- 'Arab, Juz 2, (Bairūt, Dār al-Șādir, 1300H), 1056.

24 Al-Qarāfì, Aḥmad bin Idrīs, al-Dhakhīrah fì Furūe al-Mālikiyyah, țaba': Muḥammad Ḥaji, Juz 1, (Bairūt: Dār al-Gharb al-Islāmī, 1994), 182.

25 Halal Products Research Institute, Al-Istihālah, 1, https://halal. upm.edu.my/article/al_istihalah-42973. http://www.fatawah.net/ Fatawah/597.aspx, https://islamqa.info/ar/answers/ 
حتّى تعالج بفصلها عن الأعلاف المقذرة وإعطائها علف حيواني

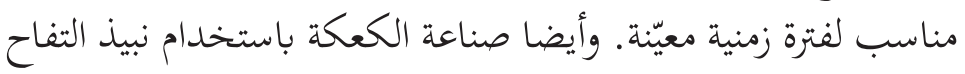

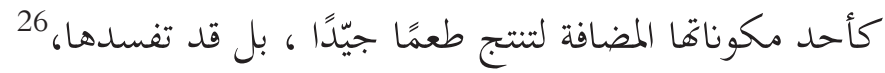
3) الاستحالة الملفى: هي عمليّة تغيير مواد الخام المحرمة الخليطة بوسائل

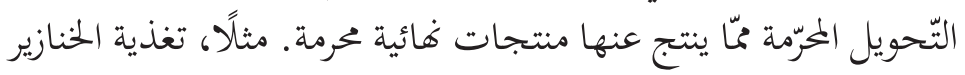

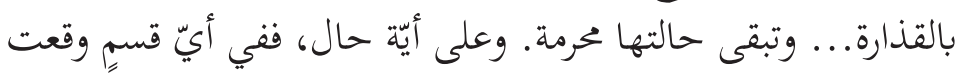

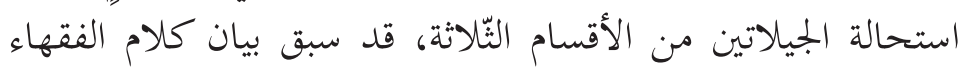

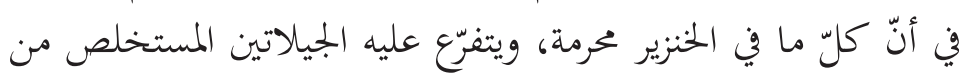

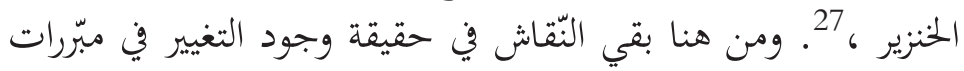
مجيزي استخدام الجيلاتين.

مبررات استخدام الجيلاتين لصناعة أدوية كبسولات

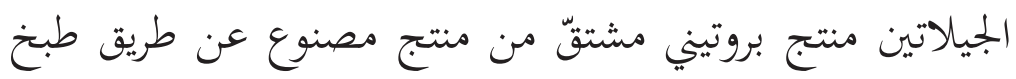
الكولاجين، حيث إنّ الكولاجين أكثر توفيرًا في جسم الحيوانات. 28 وقد ثبت علميَّا أنّ الجيالتين يلعب دورًا مهمَّاً في صحّة المفاصل

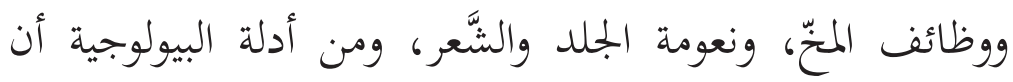
مكونات البروتين في الجيلاتين هو 99-98\% ويعني أن الأحماض الأمينية أكثر وفرة في الجيلاتين من الحيوانات الثدييات، الجيلاتين

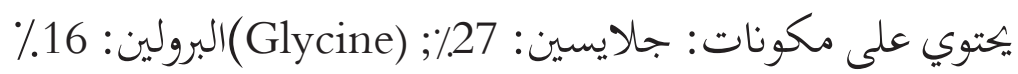

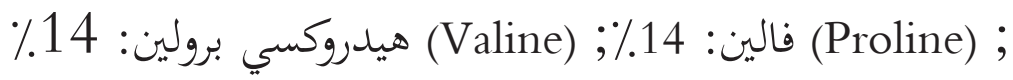

\footnotetext{
26 Ibid.

27 Ibid.

28 'Uthmān, 'Abd al-Karīm, al-Jalātīn wa Wuqū' al-Istiḥālah, 218.
} 
Glutamic) حمض الجلوتاميك: 11 مydroxyproline); (acid

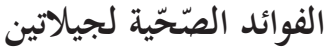

1) تحسين المفاصل والعظام: تحقّق في كثير من الأبحاث العلميّة الجيلاتين علاج لأمراض المفاصل والعظام، مثل هشاشة العظام وغيرها

2) تنعيم الجلد والشعر : جاء في بعض نتائج الفحوص المخبريّة التي

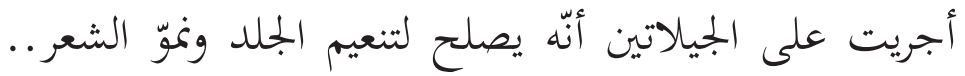

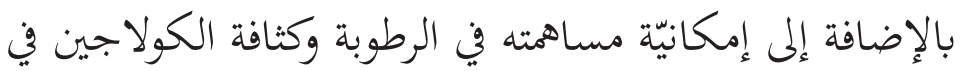

3) تعزيز وظائف الدماغ وأداء العقل: الجيلاتين غني بالجليسين

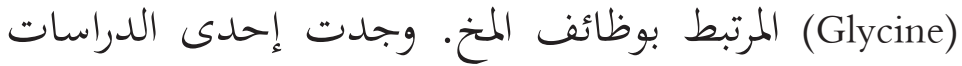

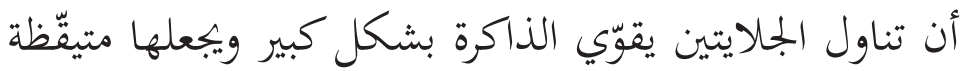

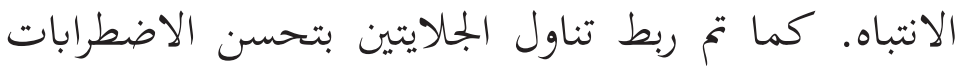
العقلية، مثل الفصام والوسواس 32.

4) يساعد الجيلاتين في إنقاص الوزن: الجيلاتين غذاء خالي من

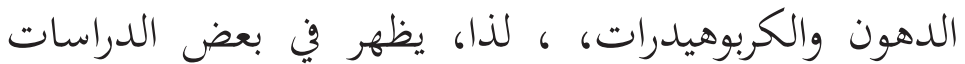

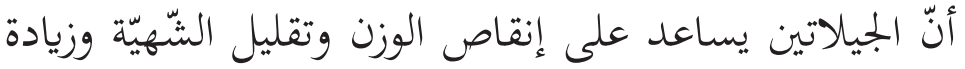

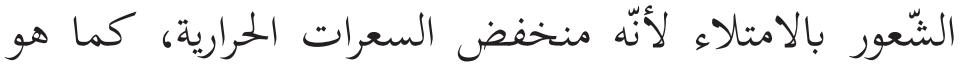

29 Alexandra Rowles, What Is Gelatin Good For? Benefits, Uses and More, (2017), https://www.healthline.com/nutrition/gelatinbenefits\#TOC_TITLE_HDR_2.

30 Ibid.

31 Ibid.

32 Ibid. 


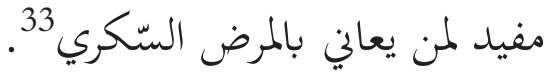

\section{نظرة مقاصديّة لاستحالة الجيلاتين واستخدامها}

من الأهداف المهمة في هذه الدراسة هو ال تحديد مدى تحقيق مقاصد

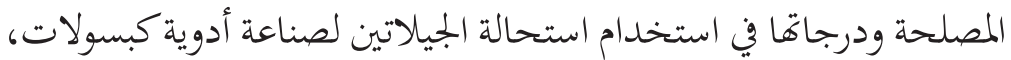

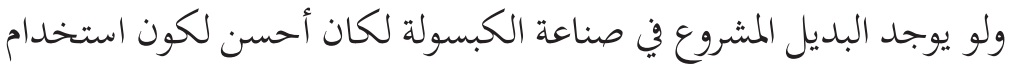

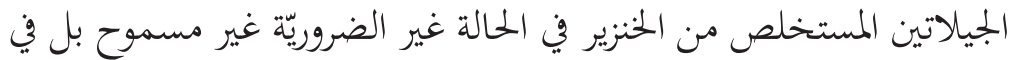

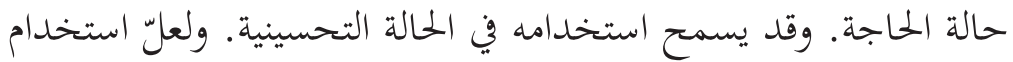

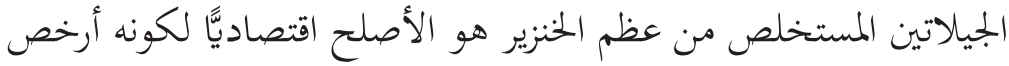

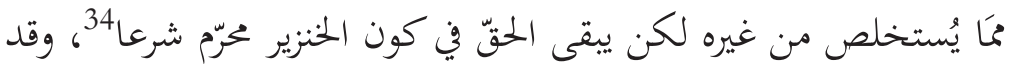

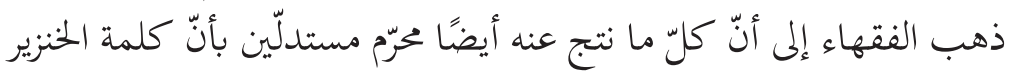

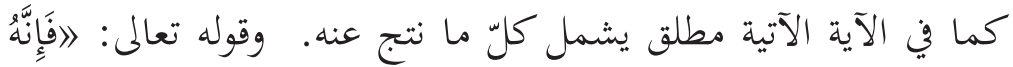

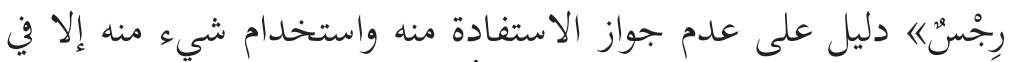

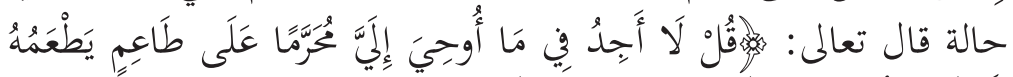

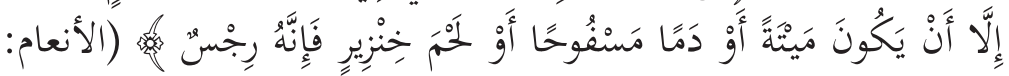
.(145

فعموم النص في الآية السيّابقة دليل على حرمة لحم الخنزير، لأنّ كلمة لحم في الآية بمعنى كل باطن وظاهر في الحنزير حرام 35 قد أجمع الفقهاء على نجاسة لحم الخنزير إلا أن هناك قول بطني بطهار الخنزير

\section{Ibid}

34 Aizhan Rakhmanova, Zaid Ashiq Khan, Rahat Sharif \& Xin Lü, Meeting the Requirements of Halal Gelatin: A Mini Review 6, no. 6 (Oklahoma USA, MOJ Food Processing \& Technology, 2018), 477.

35 Al-Ṭabarī, Muhammad bin Jarīr, Jāmi al-Bayān fì Ta'wīl Ay alQur'ān, ed. 'Abd al-Șamad (Qahirah: Markaz Buhūth wa Dirāsah Al-'Arabiyyah, 2001). 
الحي، 36 والمعتمد عند المالكية هو طهارة الحنزير حيا وأما المذبوح

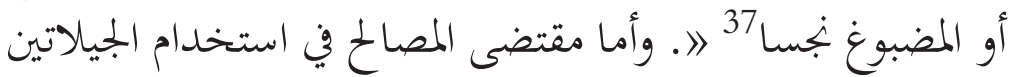
المستخلص من عظم الحنزير لا تتجاوز مصلحة اقتصاديّة

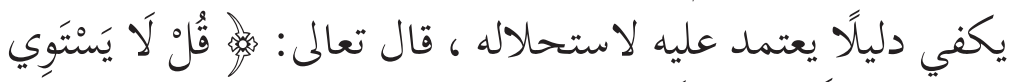

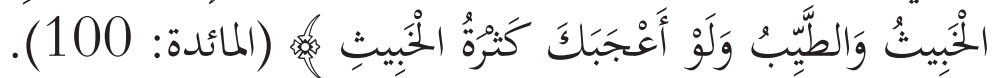
وأما ابن حزم الظاهري ذهب إلى أن كل ما في الحنزير رجس فهو

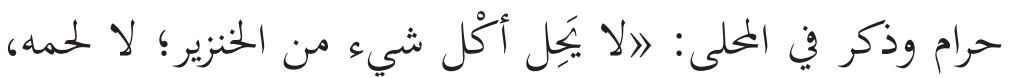

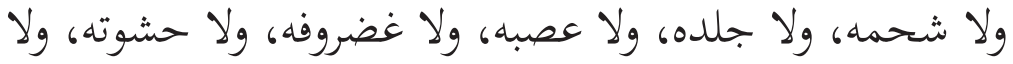

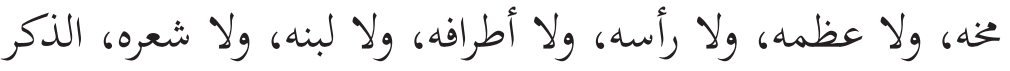

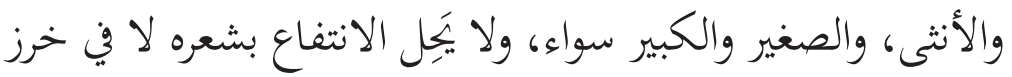
ولا غيرهن، 39

بالنظر إلى المقاصد العامة العليا للشريعة، لم يكن هناك أي دليل

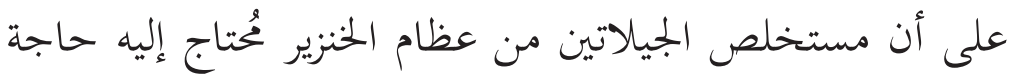

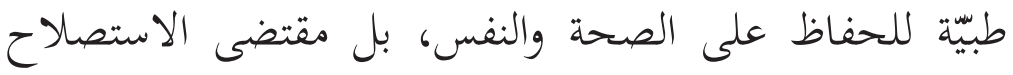

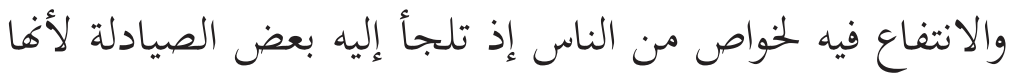

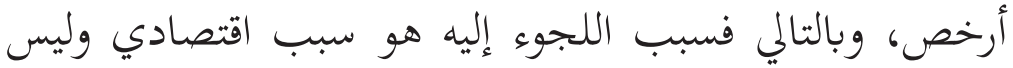

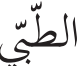

36 Al-Dardīir al- ${ }^{-}$Adwī, Aḥmad bin Muḥammad, Sharh al-Ṣaghīr ed. Musțafā Kamāl Wașfī (Qāhirah: Dār al-Ma ārif, 1201H), 64.

37 Al-Shawkānī, Muḥammad bin `Alì, Fath al-Qadīr (Bayrūt: Dār alMa rifah, 2007), 1: 135.

38 Aizhan Rakhmanova, Meeting the Requirements of Halal Gelatin: A Mini Review, 480.

39 Ibn Hazm, `Alī bin Ahmad, Al-Muhallā bi al-Āthār (Bayrūt: Dār alKutub al-'Ilmiyyah, 2003), 6: 55. 


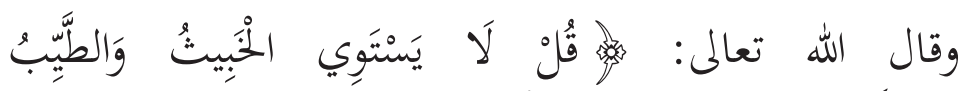

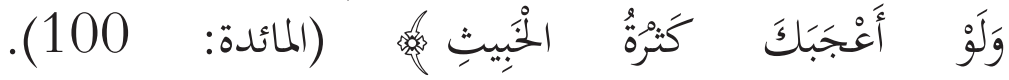

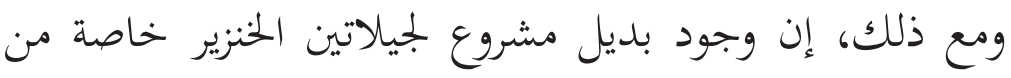

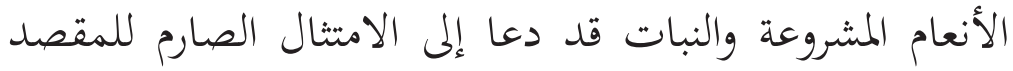

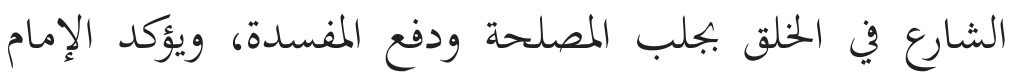

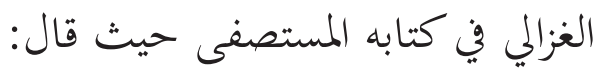

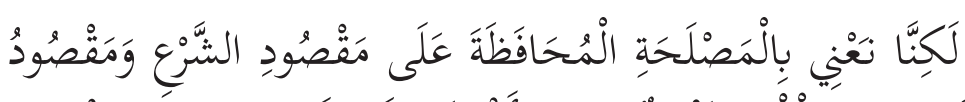

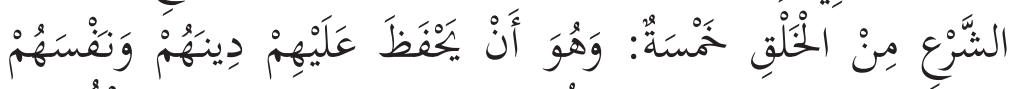

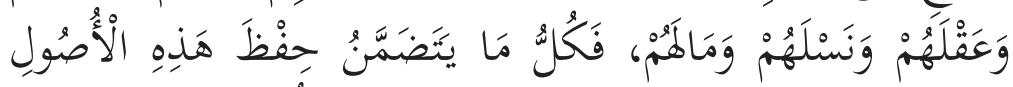

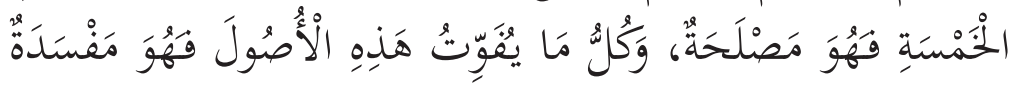

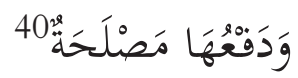

وهناك معلومات طبية تظهر القلق بشأن استخدام الجيلاتين

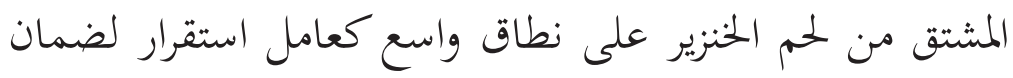

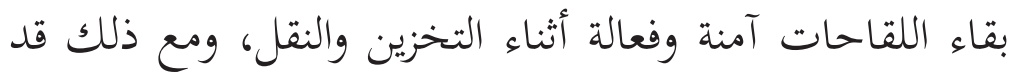
حاولت بعض الشركات على تطوير لقاحات خالية من لحم الخنزير :

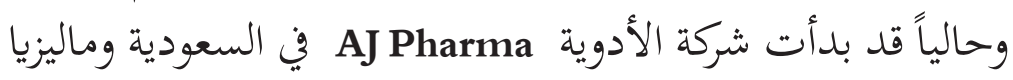

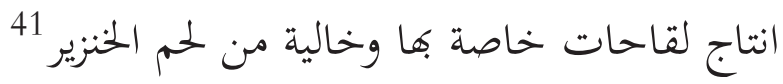

40 Al-Ghazāli, Muhammad bin Muhammad, al-Mustașfā min 'Tlm al-Ușūl, ed. Hamzha bin Zuhayr Ḥāfiz (Qāhirah: Dār al-Kutub al'Ilmiyyah, 1993), 3: 174.

41 Haaratz, Concern Among Muslims Over Pork-derived Gelatin in COVID-19 Vaccine, (2020), https://www.haaretz.com/world-news/ concern-among-muslims-orthodox-jews-over-pork-derived-gelatinin-covid-19-vaccine-1.9386477. 
النتائج

فمن خلال الدراسة استخلصنا بعض من النقاط وهي كالتالي: 1) محف الشريعة إلى حماية قيم الطبيعة البشرية وخاصة حماية الدين والحياة والفكر والأسرة والثروة.

على الرغم من أن التطور العلمي الحديث قد أكد جوهر التنقية، إلا

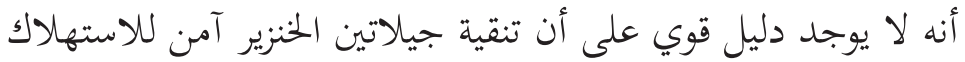
من خلال إنتاج الأدوية.

2) الجيلاتين عبارة عن: البروتينات المستخلصة من المادة اللاصقة، لأنسجة الجلود أو العظام الحيوانية، بعد معاملتها بطرق كينات كيميائية

3) حرمت الشريعة أكل الخنزير، وبالتالي لا يجموز الحصول على العظم

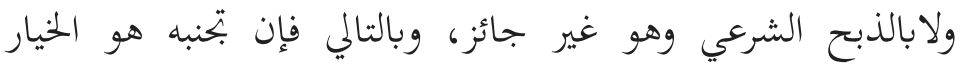
الأفضل.

4) اتفق الفقهاء على أن الحنزير لا تعمل فيه الذكاة، فلا تطهر أجزاؤه ولا

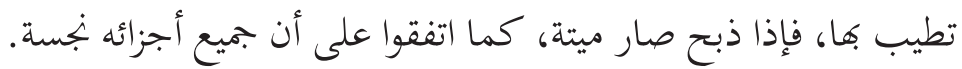
اختلف الفقهاء في حكم طهارة أجزاء الخنزير وغيرها من الأعيان

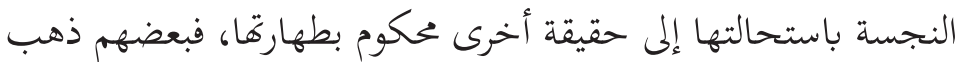

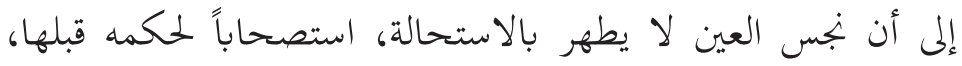
مادامت عينه باقية، وذهب بعض إنب آخر منهم إلى طهارته بها، قياساً

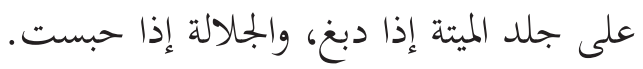

5) في العصر الحديث، على الرغم من الادعاء بإمكانية تنقية جيلاتين

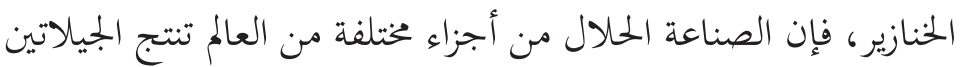

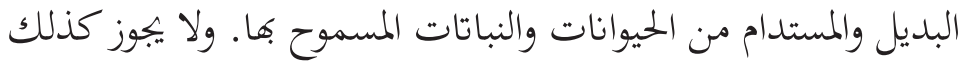
تناول الأدوية المشتملة على جيلاتين خنزيري في حال الاختيار، لماتسات 
سبق، ولا تدعو الضرورة إلى تناول مثل هذه الأدوية، لوجود كثير منها

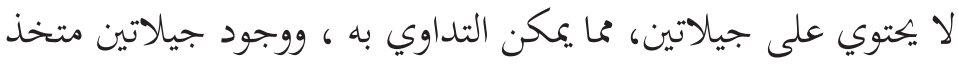

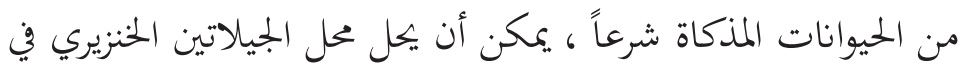

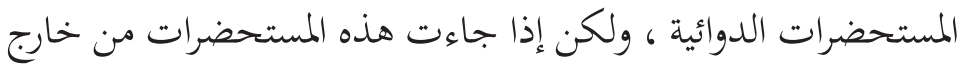

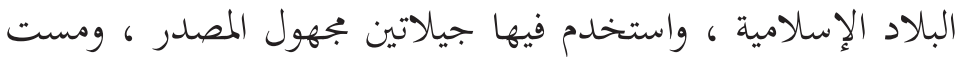

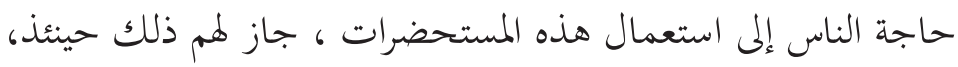

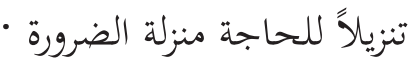

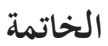

من خلال الدراسة يتبين موقف الشريعة الإسلامية من القضايا الطبية

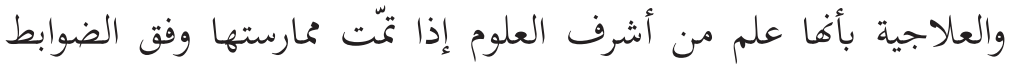

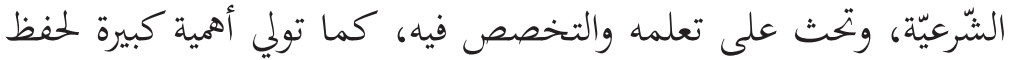

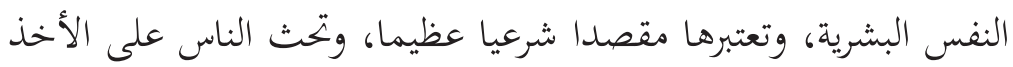
بأسباب الوقاية والعلاج حفاظا على أبداهم.

الشريعة الإسلامية بتعل الشخص أو الفرد مسؤولا على صحته،

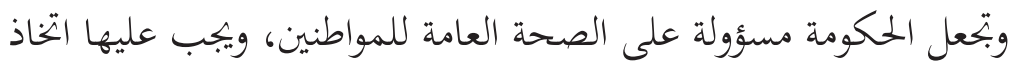

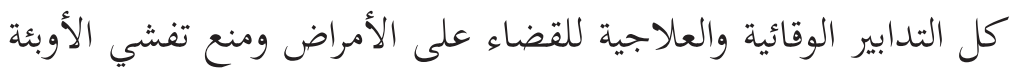

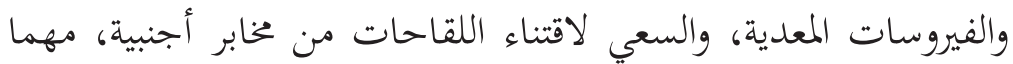

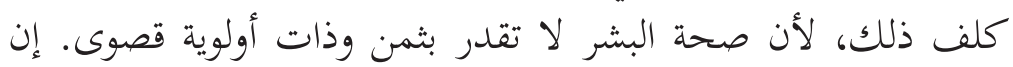

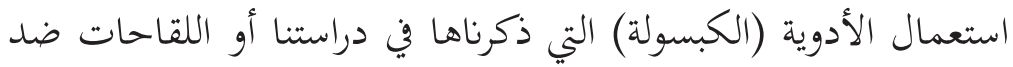
الفيروسات يخضع لجملة من القواعد الشرعية التي تبيح استعماله إذاكان

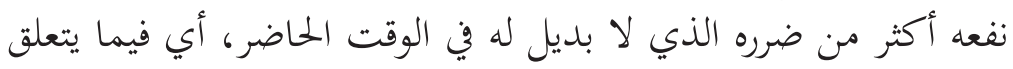

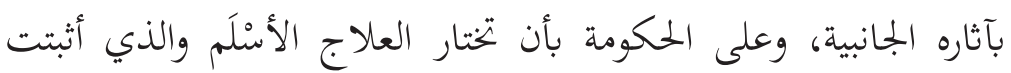

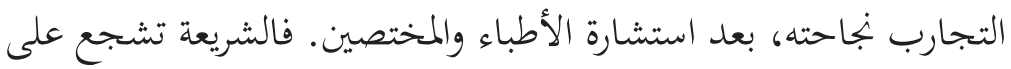
محارسة الطب وإنتاج وتصنيع الأدوية، وعلى الحلكومة بأن تثق في الباحثين 


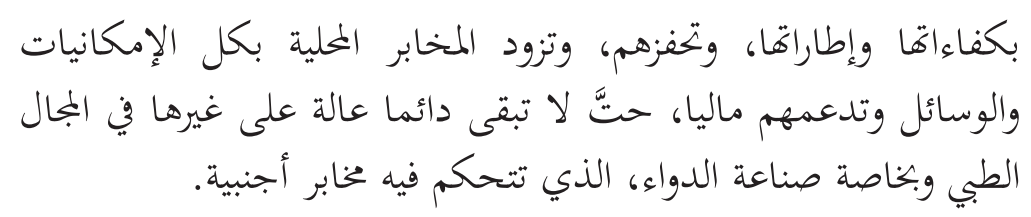

\section{REFERENCES}

'Uthmān, 'Abd al-Karīm, al-Jalātin wa Wuqū' al-Istihālah: Dirāsah min Manzūr kimiyā '̄ Tasn̄̄' wa min Manzūr Fiqh Tahsīlī, vol. 33. 50. Lahore: Majallah al-Adwā', 2018.

Abdul Rahim, Halimah, Hasan Ahmad \& Mohd Hasbi Ab. Rahim. "Theoretical Concept of Istihalah in Gelatine Application: A Review." International Social Science and Humanities Journal 3, no. 2 (2020), 142.

Alexandra Rowles. "What Is Gelatin Good For? Benefits, Uses and More," (2017), https://www.healthline.com/nutrition/ gelatin-benefits\#TOC_TITLE_HDR_2.

Al-Bābiratī, Muhammad bin Muhammad, al-'Ināyah Sharh alHidāyah. Dimashq: Dār al-Fikr, n.d., 10.

Al-Baghawī, al-Husayn bin Mas'ūd, Ma àlim Tanzīl fì Tafsìr alQur'an. Bayrūt: Dār Ihyā’ Turāth al-'Arabì, 1997.

Al-Dardīr al-'Adwī, Aḥmad bin Muḥammad, Sharh al-Saghīr, ed. Musțafā Kamāl Wașfī. Qāhirah: Dār al-Ma'ārif, 1201H.

Al-Fayūmi al-Muqrī, Aḥmad bin Muhammad bin `Alī, al-Miṣbāh al-Munīr fì Gharīb al-Sharh. Bayrūt: Maktabah al-Lubnān, 1987.

Al-Ghazālì, Muḥammad bin Muhammad, al-Mustașfā min 'Tlm al- 'Ușūl, ed. Hamzah bin Zuhayr Ḥāfizẹ, Juz 3. Qāhirah: Dār al-Kutub al-'Ilmiyyah, 1993.

Haaratz, Concern Among Muslims Over Pork-derived Gelatin in COVID-19 Vaccine, (2020), https://www.haaretz.com/ world-news/concern-among-muslims-orthodox-jews-overpork-derived-gelatin-in-covid-19-vaccine-1.9386477.

Halal Products Research Institute, Al-Istihālah, 1, https://halal.upm. edu.my/article/al_istihalah-42973. http://www.fatawah.net/ Fatawah/597.aspx, https://islamqa.info/ar/answers/ 
Hamadah Nur Lubis, Noor Faizah Mohd-Naim, Nur Nazurah Alizul \& Minhaz Uddin Ahmed. "From market to food plate: Current trusted technology and innovations in halal food analysis." Trends in Food Science \& Technology 58 (2016), 55-68.

Ibn `Abd al-Bar, Abu `Amr Yūsuf bin `Abdillah. al-Istidhkār: alJāmi`li Madhā'ib al-Fuqahā'. Qāhirah: Dār al-Wa'y, 1993.

Ibn Bațtāl, 'Ali bin Khalaf. Sharh Șaḥịh al-Bukhārī li Ibn Baṭtāl, Juz 6. Riyād, Maktab al-Rushd, 2003.

Ibn Kathīr, Ismā'īl bin 'Umar. Tafsīr-al-Qur'ān al- 'Azìm, S. bin M. Al-Salāmah (ed.); 2nd ed. Bayrut: Dār Țībah, 1997.

Ibn Manzūr, Muḥammad bin Mukrim, Lisān al-'Arab, Juz 2. Bayrut, Dār al-Șādir, 1300H.

Mariod, Abdalbasit Adam \& Adam, Hadia Fadol. "Review: Gelatin, Source, Extraction and Industrial Applications." Acta Sci. Pol., Technol. Aliment 12, no. 2 (2013), 135-147.

Mohammad Aizat Jamaludin, Mohd Anuar Ramli, Dzulkifly Mat Hashim \& Suhaimi Ab Rahman. "Fiqh Istihalah: Integration of Science and Islamic Law." Revelation and Science 2, no. 2 (2012), 117-123.

Mujtama Fiqh. "al-Qarār al-Thālith bi Sha'n Istifādāṭ al-Muslimīn min 'Iẓami al-Hayawanāt wa Julūdihā fī Sinā’h al-Jalātin." Qarārāt al-Dawrah al-Khāmisah Asharah al-Mun aqidah, Makkah, 31 ${ }^{\text {st }}$ Oct. 1988.

Al-Munjid, Muḥammad Șāliḥ, Hukm al-`Amal fĩ Tawzīe Mawād Gadhāiyyah taḥtawī ‘alā Mādah al-Jalātin al-Mustakhrijah min al-Khinzīr, (2017).

Al-Nawawì, Yahyā bin Sharf, al-Majmū `Sharh al-Muhadhdhab, Ta 'liq: Muhamad Najīb Mutīe , Juz 2. Jeddah, Maktabah alIrshād, 1970.

Al-Qarrāfì, Aḥmad bin Idrīs, al-Dhakhīrah fì Furū' al-Mālikiyyah, Muhammad Ḥají, Juz 1. Bayrūt: Dār al-Gharb al-Islāmī, 1994.

Al-Qurțubi, Muhammad bin Aḥmad, al-Jāmi li Ahkām al-Qur'ān, ed. 'Abd Allah bin 'Abd al-Muhsin al-Turqī. Qahirah: alRisalah Publisher, 2006. 
Rakhmanova, Aizhan; Khan, Zaid Ashiq; Sharif, Rahat \& Xin

Lü, Meeting the requirements of halal gelatin: A minireview 6, no. 6. Oklahoma USA: MOJ Food Processing \& Technology, 2018.

Al-Rāzī, Muḥammad bin 'Umar, Mafātīḥ al-Ghayb, Juz 5. Dimashq: Dār al-Fikr, 1981.

Al-Shawkān̄̄, Muhammad bin `Alī, Fatḥ al-Qad̄̄r, Juz 1. Bayrūt: Dār al-Ma rifah, 2007.

Al-Ṭabarī, Muḥammad bin Jarīr. Jāmi al-Bayān fì Ta'wīl Ay alQur'an, ed. 'Abd al-Șamad. Qahirah: Markaz Buhūth wa Dirāsah Al-`Arabiyyah, 2001.

Yoneciti. "Istiḥālah al-Jalātin Bayn al-'Ilm wa al-Fiqh, Halal Certification from Turkey," (2015), http://www. halalcertificationturkey.com/ar/2015/01/28

Zuhaylī, Wahbah, al-Fiqh al-Islāmī wa Adillatuh, Juz 1. Suriya: Dār al-Fikr, 1985. 